ISAHP Article: Ferretti/ /Strategic Assessment and skyscrapers: an application of the ANP, Submitted to the International Symposium of the Analytic Hierarchy Process 2014, Washington D.C., U.S.A.

\title{
STRATEGIC ASSESSMENTS AND SKYSCRAPERS: AN APPLICATION OF THE ANP
}

\author{
Valentina Ferretti \\ Department of Regional and Urban Studies and Planning \\ Politecnico of Torino \\ Torino, Italy \\ E-mail: valentine.ferretti@polito.it
}

\begin{abstract}
Territorial transformation processes can be seen as complex decision problems, due to the presence of multiple conflicting objectives, many different stakeholders to be involved, high levels of uncertainty associated with the decision outcomes, long term consequences, the presence of intangible elements and the spatial distribution of the different impacts.

The present research aims at providing urban planners, as well as other stakeholders and decision makers, with a scientifically sound and practical approach to supporting the strategic planning and evaluation phase in urban areas. Since the last decades Strategic Environmental Assessment (SEA) has been recognized as a very important and rapidly growing area of research and application in the domain of sustainable development.

This paper thus proposes and tests the development of a complex ANP analysis, based on the definition of Benefits, Costs, Opportunities and Risks for a complex territorial transformation involving the construction of a new skyscraper in the city of Torino (Italy). The idea below these projects is that the construction of the new tall buildings represents the possibility of creating important architectural landmarks, both at the urban and at the territorial level.

As a result, key planning priorities and weaknesses are identified to support the subsequent decision-making phase.
\end{abstract}

Keywords: environmental assessments, skyscrapers, BOCR, focus group, urban planning.

\section{Introduction}

Territorial transformation processes can be seen as complex decision problems, due to the presence of multiple conflicting objectives, many different stakeholders to be involved, high levels of uncertainty associated with the decision outcomes, long term consequences, the presence of intangible elements and the spatial distribution of the different impacts. New urban landscapes are being shaped and a particularly interesting area of interdisciplinary research is the one concerning skyscrapers projects.

This paper describes the development of a real decision-making process related to the construction of a new skyscraper in the city of Torino (Italy). In particular the study highlights the role of a Multicriteria Decision Support process to support the Strategic Evaluation Assessment.

The research question driving the study can be summarized as follows: 
IJAHP Article: Ferretti//Strategic Assessment and skyscrapers: an application of the ANP, Submitted to the International Symposium of the Analytic Hierarchy Process 2014, Washington D.C., U.S.A.

"Which is the contribution of the Analytic Network Process (ANP) in the context of sustainability assessment of urban transformation processes?"

The study thus aims to investigate how the ANP can shape the decision process and support in the identification of the opportunities and the risks that a territorial transformation such as the construction of a skyscraper can create.

The importance of the study stems from the innovative context of application of the ANP and from the focus on the participative decision process.

\section{Literature Review}

Since the last decades Strategic Environmental Assessment (SEA) has been recognized as a very important and rapidly growing area of research and application in the domain of sustainable development. It has been generally agreed that public participation must be integrated in SEA procedure because it allows information relevant to the decisionmaking process to be included. In this sense, one of the major challenge in this area is to detect some tools which are able to better link the decision-making process and the stakeholders involved in the decision (Bottero et al., 2014).

A very large and consolidated amount of literature concerning the ANP exists in different fields. Applications in the context of sustainability assessments for complex territorial transformation processes are still scarce and there is thus a need to provide integrated approaches and best practices able to support both researchers and practitioners.

\section{Hypotheses/Objectives}

The study aims to investigate how the ANP can shape the decision process and support in the identification of the opportunities and the risks that a territorial transformation such as the construction of a skyscraper can create.

The paper will focus on how the evaluation was accomplished by a participated approach. Therefore, the central questions discussed in the paper are as follows:

1) How can the MCDA evaluation be integrated in the strategic evaluation procedure?

2) Can the MCDA approach be a link for connecting science and policy making (Tsoukias, 2011)?

\section{Research Design/Methodology}

The reasons for using an ANP-based decision approach in the present analysis are: (i) the development of a new urban landscape is a multicriteria problem since it has impacts on different dimensions; (ii) there are dependencies among groups of criteria which need to be analyzed, and (iii) the detailed analysis of the interrelationships between criteria forces the Decision Makers (DMs) to carefully reflect on their project priority approach and on the decision-making problem itself. This helps DMs to gain a better understanding of the problem and to make a more reliable final decision.

In particular, the model has been created through the organization of a focus group of experts.

The use of experts' panels for the development of the evaluation expands the knowledge basis and may serve to avoid the possible biases, which characterize the situation with a 
IJAHP Article: Ferretti//Strategic Assessment and skyscrapers: an application of the ANP, Submitted to the International Symposium of the Analytic Hierarchy Process 2014, Washington D.C., U.S.A.

single expert. On the other side, the use of experts' panels has a range of problems associated with it, such as the panel composition, the interaction mode between panel members and, above all, the aggregation of panel responses into a form useful for the decision (Beinat, 1997). In our case, particular attention was dedicated to the panel composition in order to have it balanced.

The experts participating to the focus group brainstormed together with reference to both the definition of criteria and the weighing procedure up to the point in which they reached a consensus. By facilitating the discussion and evaluation process by means of an analyst expert on Multicriteria Analysis, inconsistencies were corrected in real time.

From the methodological point of view, the development of the decision model involved the following different steps:

(i) structuring of the decision problem in terms of criteria, sub-criteria and specific actions;

(iii) weighing of all the considered factors based on both the results of the participative procedure and on technical and experts judgments;

(iv) aggregation of the results in order to obtain a priority list of the alternative options;

(v) validation of the model through a sensitivity analysis

\section{Data/Model Analysis}

Table 1 shows the BOCR elements considered in the analysis.

Table 1 The BOCR elements

\begin{tabular}{|c|c|c|}
\hline BOCR & Clusters & Elements \\
\hline \multirow[t]{10}{*}{ Benefits } & Economic aspects & New land uses \\
\hline & & Real estate improvement \\
\hline & Energy related aspects & Optimization in the consumption \\
\hline & & Use of renewable sources of energy \\
\hline & Logistic aspects & Efficacy and efficiency \\
\hline & & Enhancement of the interconnections \\
\hline & Social aspects & New services \\
\hline & & Comfort \\
\hline & Urban aspects & Revitalization \\
\hline & & Synergies with ongoing transformations \\
\hline \multirow[t]{11}{*}{ Costs } & Environmental aspects & Construction impacts \\
\hline & & Emissions \\
\hline & & Landscape impacts \\
\hline & Economic aspects & Construction costs \\
\hline & & Transfer costs \\
\hline & & Time \\
\hline & Energy related aspects & Resources consumption \\
\hline & Logistic aspects & Centrality \\
\hline & & Road impacts \\
\hline & Social aspects & Impacts during the construction works \\
\hline & & Transfer of the personnel \\
\hline \multirow[t]{2}{*}{ Opportunities } & Environmental aspects & Soil quality \\
\hline & & Long term improvements \\
\hline
\end{tabular}


IJAHP Article: Ferretti/ /Strategic Assessment and skyscrapers: an application of the ANP, Submitted to the International Symposium of the Analytic Hierarchy Process 2014, Washington D.C., U.S.A.

\begin{tabular}{|l|l|l|}
\hline \multirow{4}{*}{} & Economic aspects & Creation of a development pole \\
\cline { 2 - 3 } & & Valorization of the territorial context \\
\cline { 2 - 3 } & Urban aspects & Creation of new symbols \\
\cline { 2 - 3 } & & New mixed pole \\
\hline \multirow{4}{*}{ Eisks } & Environmental aspects & Waste production \\
\cline { 2 - 3 } & & Impact on underground water \\
\cline { 2 - 3 } & Impact on fauna \\
\cline { 2 - 3 } & & New traffic flows \\
\cline { 2 - 3 } & Economic aspects & Industrial accident risk \\
\cline { 2 - 3 } & Logistic aspects & Management costs \\
\cline { 2 - 3 } & Social aspects & Lack of sharing of the project \\
\cline { 2 - 3 } & Urban aspect & Dispersion of tall building over the city \\
\cline { 2 - 3 } & & City integration \\
\hline
\end{tabular}

Two strategic alternatives have been considered for the analysis: the "inertial" alternative and the "masterplan" alternative.

Figure 1 illustrates the project of the new skyscraper under analysis for the city of Torino (Italy).

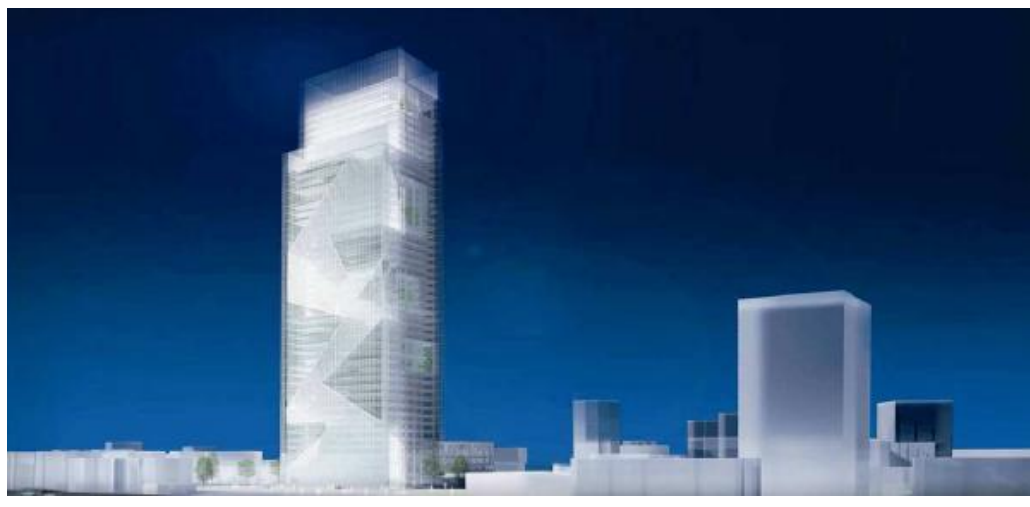

Figure 1 The project for a new skyscraper in the city of Torino

As a result of the weighing procedure a final priority ranking has been obtained for all the elements in each subnetwork.

Table 2 provides as an example the limit supermatrix for the Opportunities subnetwork. The consistency index has been carefully checked for all the pairwise comparison matrices in order to have it lower than 0,10 for the whole model.

\section{Limitations}

An important limitation of the study is represented by the high number of questions that the experts involved in the focus group had to answer. In order to reduce the cognitive burden on the expert and make the participative process more efficient we will investigate how to select a subset of key questions from which to derive the remaining answers. 
IJAHP Article: Ferretti//Strategic Assessment and skyscrapers: an application of the ANP, Submitted to the International Symposium of the Analytic Hierarchy Process 2014, Washington D.C., U.S.A.

Future improvements of the work also refer to the development of a sensitivity analysis with reference to both the weights of the criteria and the weights of the clusters.

Table 2 Limit supermatrix for the opportunities subnetwork

\begin{tabular}{|c|c|c|c|c|c|c|c|c|c|}
\hline & \multicolumn{2}{|c|}{ Alternatives } & \multicolumn{2}{|c|}{$\begin{array}{l}\text { Environmental } \\
\text { aspects }\end{array}$} & \multicolumn{2}{|c|}{$\begin{array}{l}\text { Economic } \\
\text { aspects }\end{array}$} & \multicolumn{2}{|c|}{ Urban aspects } \\
\hline & & Masterpla & Inertial & A1 & $\mathrm{A} 2$ & E1 & E2 & $\mathrm{U} 1$ & $\mathrm{U} 2$ \\
\hline \multirow{2}{*}{$\dot{+}$} & Masterpla & 0,403 & 0,403 & 0,403 & 0,403 & 0,403 & 0,403 & 0,403 & 0,403 \\
\hline & Inertial & 0,086 & 0,086 & 0,086 & 0,086 & 0,086 & 0,086 & 0,086 & 0,086 \\
\hline \multirow{2}{*}{$\dot{\overrightarrow{\mid}}$} & A1 & 0,053 & 0,053 & 0,053 & 0,053 & 0,053 & 0,053 & 0,053 & 0,053 \\
\hline & $\mathrm{A} 2$ & 0,07 & 0,07 & 0,07 & 0,07 & 0,07 & 0,07 & 0,07 & 0,07 \\
\hline \multirow{2}{*}{$\dot{8}$} & E1 & 0,024 & 0,024 & 0,024 & 0,024 & 0,024 & 0,024 & 0,024 & 0,024 \\
\hline & E2 & 0,017 & 0,017 & 0,017 & 0,017 & 0,017 & 0,017 & 0,017 & 0,017 \\
\hline \multirow{2}{*}{$\dot{0}$} & U1 & 0,259 & 0,259 & 0,259 & 0,259 & 0,259 & 0,259 & 0,259 & 0,259 \\
\hline & $\mathrm{U} 2$ & 0,088 & 0,088 & 0,088 & 0,088 & 0,088 & 0,088 & 0,088 & 0,088 \\
\hline
\end{tabular}

\section{Conclusions}

The paper illustrates the application of the ANP to the decision problem concerning a complex urban planning process.

The results of the study highlight the relationship between the performed evaluation, the strategic assessment procedure and the participatory planning process that has been carried out.

The proposed approach thus seemed to constitute a real integrated decision support tool able to both generate and compare alternative options, thus aiding strategic thinking about the likely environmental, social and economic consequences of current and possible future trends and the consequences of making particular policy choices.

Finally, we can affirm that one of the most significant strengths of the adopted methodology is represented by the fact that the DM gains more awareness of the elements at stake while structuring the model and thus learns about the problems while solving them.

\section{Key References}

Beinat E. 1997. Value functions for environmental management. Kluwer Academic Publishers, Dordrecht, Boston.

Bottero M., Ferretti V., Mondini G., Pomarico S. 2014. Enabling public participation in Strategic Environmental Assessment: an application of Multicriteria Analysis, Strategic Behavior and the Environment, ISSN: 1944-0138 (in press).

Tsoukias, A. 2011a. Methods and Tools for Public Policy Evaluation, Working paper, LAMSADE-CNRS, Université Paris-Dauphine, Paris. Available at http://www.lamsade.dauphine.fr/ tsoukias/teaching.htm 